\title{
BUDAYA JAWA IBU POSTPARTUM DI DESA CANDIREJO KECAMATAN NGAWEN KABUPATEN KLATEN
}

\author{
Sugita, Nurul Herlina Widiastuti \\ Kementerian Kesehatan Politeknik Kesehatan Surakarta Jurusan Kebidanan
}

\begin{abstract}
Java Culture, Mrs. Post Partum. The purpose of this study is to describe the culture of Java on postpartum mothers in the village Candirejo Ngawen District of Klaten district. This research is descriptive quantitative research subjects across the capital after the postpartum period ending at 24 samples. Technical analysis of the data used is descriptive test. The results showed that $16.66 \%$ of mothers after the postpartum period wear pilis 0-40 days, $25 \%$ use them less than 40 days, $37.5 \%$ were taking parem in the hands and feet for 40 days, 75\% drink herbal rice kencur, 87, 5\% herbal drink wejahan, 37.5\% herbal drink papaya leaves, $8.33 \%$ herbal drink turmeric tamarind, ginger herbal drink 4,16\%, 37.5\% herbal drink uyup-uyup, 37.5\% do masage, 58, 33\% do walik bye at the time selapanan, $37.5 \%$ were taking octopus knot, wearing a corset $8.33 \%$, 50\% wear stagen 4 meters long, $41.66 \%$ were taking stagen along 10 meters, 50\% do kempitan less than 40 day, $95.83 \%$ did sit senden less than 40 days, $66.66 \%$ abstain from eating spicy, 33.33\% abstaining stimulating, $4.16 \%$ abstain from drinking a lot, $12.5 \%$ abstinence drinking ice, $8.33 \%$ abstain from eating sugary foods, $87.5 \%$ sat straight legs, a $100 \%$ sat feet together, parallel, not hanging and $75 \%$ sat with his feet propped up a small chair.
\end{abstract}

Keywords: Java Culture, Mother Postpartum

\begin{abstract}
Abstrak: Budaya Jawa, Ibu Postpartum. Tujuan penelitian ini adalah untuk mengetahui gambaran budaya jawa pada ibu postpartum di Desa Candirejo Kecamatan Ngawen Kabupaten Klaten. Jenis penelitian ini merupakan diskriptif kuantitatif dengan subyek penelitian seluruh ibu pasca periode postpartum berakhir sebesar 24 sampel. Tehnik analisis data yang digunakan adalah uji diskriptif. Hasil penelitian menunjukkan bahwa $16,66 \%$ ibu pasca periode postpartum memakai pilis 0-40 hari, 25\% memakainya kurang dari 40 hari, 37,5\% memakai parem di tangan dan kaki selama 40 hari, $75 \%$ minum jamu beras kencur, 87,5\% minum jamu wejahan, 37,5\% minum jamu daun papaya, 8,33\% minum jamu kunir asem, 4,16\% minum jamu temulawak, 37,5\% minum jamu uyup-uyup, 37,5\% melakukan masage, 58,33\% melakukan walik dadah pada waktu selapanan, 37,5\% memakai gurita simpul, 8,33\% memakai korset, 50\% memakai stagen sepanjang 4 meter, 41,66\% memakai stagen sepanjang 10 meter, 50\% melakukan kempitan kurang dari 40 hari, 95,83\% melakukan duduk senden kurang dari 40 hari, 66,66\% pantang makan pedas, 33,33\% pantang makan merangsang, 4,16\% pantang minum banyak, $12,5 \%$ pantang minum es, $8,33 \%$ pantang makan makanan manis, $87,5 \%$ duduk kaki lurus, $100 \%$ duduk kaki rapat, sejajar, tidak menggantung dan $75 \%$ duduk dengan kaki diganjal kursi kecil.
\end{abstract}

Kata Kunci: Budaya Jawa, Ibu Postpartum 


\section{PENDAHULUAN}

Di dalam masyarakat kebudayaan sering diartikan sebagai the general body of the arts, yang meliputi seni sastra, seni musik, seni pahat, seni rupa, pengetahuan filsafat atau bagianbagian yang indah dari kehidupan manusia. Dalam penggunaan cara hidup pengertian kebudayaan ditempatkan disamping pengertian ekonomi, politik, hukum, sedang dalam pengertian ilmu sosial kebudayaan adalah seluruh cara hidup sesuatu masyarakat. Hasil buah budi (budaya) manusia itu dapat kita bagi menjadi 2 macam yaitu kebudayaan material (lahir) yaitu kebudayaan yang berwujud kebendaan, misalnya: rumah, gedung, alat-alat senjata, mesin-mesin, pakaian dan sebagainya dan kebudayaan immaterial (spiritual=batin), yaitu: kebudayaan, adat istiadat, bahasa, ilmu pengetahuan dan sebagainya (Prasetya, 1991).

Menurut Marmi (2000) masa postpartum adalah masa dimulai beberapa jam sesudah lahirnya plasenta sampai 6 minggu setelah melahirkan. Masa postpartum dimulai setelah kelahiran plasenta dan berakhir ketika alat-alat kandungan kembali seperti keadaan sebelum hamil yang berlangsung kira-kira 6 minggu. Perawatan masa postpartum mencakup berbagai aspek mulai dari pengaturan dalam mobilisasi, anjuran untuk kebersihan diri, pengaturan diet, pengaturan miksi dan defekasi, perawatan payudara (mamma) yang ditujukan terutama untuk kelancaran pemberian Air Susu Ibu guna pemenuhan nutrisi bayi, dan lain-lain (Mochtar, 1998). Selain perawatan postpartum dengan memanfaatkan system pelayanan biomedical, ada juga ditemukan sejumlah pengetahuan dan perilaku budaya dalam perawatan masa postpartum. Para ahli antropologi melihat bahwa pembentukan janin, kelahiran dan masa pasca kelahiran umumnya dianggap oleh berbagai masyarakat diberbagai penjuru dunia sebagai peristiwa-peristiwa yang wajar dalam kehidupan manusia. Namun respon masyarakat terhadap berbagai peristiwa kehidupan ini bersifat budaya, yang tidak selalu sama pada berbagai kelompok masyarakat (Manurung, 2009).

Di Indonesia terdapat pluralisme sistem penyembuhan dimana berbagai cara pengobatan yang berbeda-beda hadir berdampingan termasuk humoral medicine dan elemen magis. Salah satu suku yang ada di Indonesia adalah Jawa, yang merupakan suku terbanyak, pada masyarakat suku jawa mempunyai cara-cara tertentu dalam penyembuhan dan mempunyai persepsi tertentu tentang sehat sakit terkait budaya yang dianut (Pratiwi, Arifah, 2011), hal tersebut sesuai dengan hasil penelitian Suryawati tahun 2007 di Kabupaten Jepara dari 60 ibu postpartum 41,7\% responden berpantang mengkonsumsi daging dan ikan, 83,3\% responden melakukan pijat badan untuk mengembalikan kebugaran tubuh dan minum jamu dilakukan hampir oleh semua responden. Sedangkan temuan pada penelitian yang dilakukan oleh Pratiwi dan Arifah (2011) di Kabupaten Sukoharjo teridentifikasi alasan keluarga yang mempunyai perilaku budaya pada masa postpartum diantaranya makanan pantangan bagi ibu postpartum adalah gorengan, cabe dengan kebanyakan alasan menghambat penyembuhan luka sehabis melahirkan, adapula seorang ibu yang memberikan alasan tidak boleh makan ikan asin dan makanan 
amis lainnya karena nanti ASI menjadi amis, kemudian menganjurkan minum jamu dan daun katu untuk memperlancar ASI, ibu postpartum tidak boleh tidur telentang karena dapat menyebabkan darah putih naik ke mata, tidak dianjurkan kaki ditekuk dan kerja berat, duduk kaki harus lurus, memakai pilis di dahi, tidak boleh banyak gerak, memakai stagen, perut diberi tapel, tidur setengah duduk serta mandi wuwung pagi dan sore.

Berdasarkan studi pendahuluan yang dilakukan di Bidan Desa Candirejo Kecamatan Ngawen Kabupaten Klaten dari hasil wawancara pada ibu-ibu yang kontrol setelah melahirkan adalah ibu memakai stagen, pilis, kempitan dan minum jamu, sehingga perlu dikaji lebih dalam bagaimanakah gambaran budaya jawa pada ibu postpartum.

\section{METODE PENELITIAN}

Desain penelitian menggunakan deskriptif kuantitatif. Pada penelitian ini peneliti mengidentifikasi distribusi frekwensi perawatan postpartum yang dilakukan pada ibu postpartum di Desa Candirejo Kecamatan Ngawen Kabupaten Klaten.Populasi dalam penelitian ini adalah ibu-ibu yang berada pada rentang waktu 1 minggu setelah periode postpartum berakhir di Desa Candirejo Kecamatan Ngawen Kabupaten Klaten.Teknik pengambilan sampel yang digunakan adalah sampling jenuh dengan mengambil semua anggota populasi menjadi sampel. Adapun sampel yang diambil adalah Ibu-ibu yang telah 1 minggu melewati periode postpartum di Desa Candirejo Kecamatan Ngawen Kabupaten Klaten.Variabel dalam penelitian ini adalah budaya jawa pada ibu postpartum.
Analisa data yang dipakai dalam penelitian deskriptif menggunakan statistik deskriptif yaitu statistik yang membahas cara-cara meringkas, menyajikan dan mendeskripsikan suatu data dengan tujuan agar mudah dimengerti dan lebih bermakna. Analisa data ini akan menghasilkan distribusi dan presentase dari tiap variabel, kemudian disajikan ke dalam tabel distribusi frekuensi.

\section{HASIL PENELITIAN}

Dari hasil wawancara yang telah dilakukan terhadap dua puluh empat responden, peneliti menemukan beberapa budaya jawa yang masih umum dilakukan oleh ibu-ibu pada masa postpartum di Desa Candirejo Kecamatan Ngawen Kabupaten Klaten. Adapun menurut responden budayabudaya jawa tersebut sebagian besar dilakukan sampai hari ke-36 postpartum, yang dalam masyarakat jawa dikenal dengan istilah selapan. Budaya Jawa pada periode postpartum diantaranya memakai pilis, parem, minum jamu, pijet, walikdadah, memakai gurita, memakai stagen, kempitan, duduk senden, pantang makan dan budaya duduk.

\section{PEMBAHASAN}

Berikut paparan dari masingmasing budaya jawa pada masa postpartum:

1. Budaya jawa memakai pilis

Berdasarkan hasil penelitian diperoleh hasil sebagian kecil responden melakukan budaya jawa memakai pilis. Sebesar $25 \%$ atau enam orang memakai pilis kurang dari empatpuluh hari, sedangkan 16, $66 \%$ atau dua orang memakainya sampai empatpuluh hari. Pilis digunakan dengan cara ditempel di dahi.Pilis 
diperoleh dengan cara membeli di pasar atau tukang jamu tradisional. Alasan ibu-ibu memakai pilis adalah untuk menjaga kesejukan mata.

2. Budaya jawa Memakai parem

Dari hasil penelitian diketahui sebagian kecil responden melakukan budaya jawa memakai parem pada periode postpartum yaitu sebesar 37,5 $\%$ atau sebanyak sembilan responden, parem digunakan pada tangan dan kaki.

3. Budaya Jawa Minum Jamu

Jamu yang dikonsumsi responden merupakan jamu tradisional diantaranya jamu beras kencur, kunir asem, temulawak, godhong kates, wejahan atau jamu campuran dan jamu uyup-uyup. Sebagian besar responden mengkonsumsi jamu wejahan. Alasan responden mengkonsumsi jamu adalah 3 responden mengatakan untuk memperlancar ASI dan 22 responden lainnya mengatakan selain untuk memperlancar ASI juga untuk menjaga agar badan sehat dan padat.

4. Budaya jawa pijet

Dari hasil penelitian hanya sebagian kecil responden melakukan budaya jawa pijet pada masa postpartum. Sebanyak 6 responden memulai pijet pada hari pertama setelah bersalin, 1 responden pada hari ke- 2, 1 responden pada hari ke-3 dan 1 responden lainnya mulai pijet pada hari ketujuh setelah bersalin. Sebanyak tiga responden melakukan pijet sebanyak lima kali, lima responden melakukan pijet sebanyak tiga kali dan satu responden melakukan pijet sebanyak dua kali selama periode postpartum. Bagian yang dipijet adalah seluruh tubuh kecuali perut. Alasan responden melakukan pijet adalah untuk menghilangkan rasa lelah setelah bersalin.

5. Budaya Jawa Walikdadah
Dari hasil penelitian didapat separuh lebih dari jumlah responden yang melakukan budaya jawa walikdadah atau pengurutan yang terakhir dan daerah utama yang diurut adalah perut. Responden melakukan walikdadahan pada selapan hari atau hari ke 36 periode postpartum. Tujuan responden melakukan walikdadah adalah untuk mengembalikan posisi rahim kebentuk semula

6. Budaya jawa memakai gurita

Diperoleh hasil bahwa hanya sebagian kecil responden yang melakukan budaya jawa memakai gurita pada periode postpartum. Delapan responden memakai gurita dengan alasan mengecilkan perut dan menjaga keindahan tubuh sedangkan satu responden lainnya mengatakan alasan memakai gurita agar perut menjadi kencang.

7. Budaya jawa stagen

Terdapat sebagian besar responden memakai stagen pada periode postpartum. Ukuran panjang stagen terdiri dari dua jenis yaitu empat meter dan sepuluh meter. Dalam pemakaian stagen dengan ukuran panjang sepuluh meter para responden dibantu oleh orang lain sedangkan responden yang memakai stagen dengan panjang empat meter dapat memakainya sendiri. Alasan responen memakai stagen adalah untuk mengecilkan perut dan menjaga keindahan tubuh.

8. Budaya jawa kempitan

Separuh dari jumlah seluruh responden melakukan budaya kempitan, kempitan dilakukan kurang dari empatpuluh hari, biasanya hanya selama lokhea masih keluar. Alasan responden melakukan budaya kempitan adalah agar jalan lahir menjadi rapat kembali. 
9. Budaya jawa duduk senden

Duduk senden merupakan budaya jawa pada ibu postpartum yang dilakukan sebagian besar responden, dilakukan kurang dari empatpuluh hari. Alasan responden melakukan duduk senden adalah untuk menjaga kesehatan.

10. Budaya pantang makan

Menurut para responden terdapat budaya pantang makan pada makanan tertentu yang perlu dilakukan oleh ibuibu postpartum dengan berbagai alasan tertentu. Sebagian besar responden berpantang makan pedas atau cabai, dengan alasan anak bisa diare. Sebanyak 33, $33 \%$ atau 8 responden melakukan pantang makan pada makanan amis-amisan dengan alasan ASI menjadi amis dan luka setelah beralin tidak lekas sembuh. Sebanyak 4, $16 \%$ atau 1 responden berpantang minum banyak dengan alasan anak bisa pilek. Sebanyak 12, $5 \%$ atau 3 responden berpantang minum es dengan alasan anak bisa sakit panas atau pilek. Sebanyak 8, $33 \%$ atau 2 responden berpantang makan makanan manis dengan alasan anak bisa beleken atau sakt mata.

11. Budaya jawa duduk pada ibu postpartum

Terdapat beberapa budaya jawa duduk pada ibu postpartum dan seluruh responden melakukan budaya duduk dengan kaki sejajar tidak saling tumpang tindih, merapatkan kaki serta kaki tidak menggantung setiap kali duduk dengan alasan agar tidak varises, merapatkan kembali jalan lahir dan agar jahitan tidak rusak, serta sebagian besar responden duduk dengan kaki lurus dan diganjal kursi kecil dengan alasan supaya kaki tidak bengkak, tidak varises dan mudah menyusui.

\section{KESIMPULAN DAN SARAN}

Faktor sosial budaya mempunyai peranan penting dalam memahami sikap dan perilaku pada kehidupan manusia salah satunya adalah pada periode postpartum. Sebagian pandangan budaya telah diwariskan turun-temurun dalam kebudayaan masyarakat yang bersangkutan

Berdasarkan hasil penelitian yang diperoleh peneliti dari duapuluh empat responden mengenai gambaran budaya jawa pada ibu postpartum didapat bahwa budaya jawa pada periode postpartum yang masih dilakukan antara lain pilis, parem, minum jamu, pijet, stagenan, gurita, kempitan, walikdadah, duduk senden, pantang makan dan budaya duduk.

Dari hasil pembahasan pada bab sebelumnya, didapatkan budaya jawa pada ibu postpartum yang menunjang kesehatan ataupun yang merugikan bagi kesehatan. Budaya yang merugikan antara lain adalah $d u d u k$ senden, stagen dan pantang makan amis-amisan. Disamping hal tersebut adapula budaya jawa yang menunjang dari segi kesehatan diantaranya budaya minum jamu, budaya duduk, parem, pilis dan kempitan. Saran yang dianjurkan setelah penelitian ini adalah:

1. Keluarga dapat memberikan dukungan terhadap budayabudaya jawa yang tidak merugikan dari segi kesehatan untuk tetap dilakukan selama periode postpartum seperti menganjurkan memakai pilis, parem, minum jamu, dsb.

2. Ibu-ibu postpartum diharapkan tidak melakukan praktik budaya jawa yang merugikan bagi kesehatan pada periode postpartum seperti tidak perlu 
melakukan duduk senden,memakai stagen ataupun pantang makan.

3. Penelitian lebih lanjut dapat dilakukan lebih mendalam dan memperluas daerah penelitian serta spesifikasi pada budaya tertentu.

\section{DAFTAR RUJUKAN}

Marmi. 2012, Asuhan Kebidanan Pada Masa Postpartum, Pustaka Pelajar, Yogyakarta

Manurung,Y. D. 2009, Perawatan Postpartum Menurut Budaya Jawa, [Karya Tulis Ilmiah]. Program D-IV Bidan Pendidik Fakultas Kedokteran Universitas Sumatra Utara

Mochtar, R.,1998, Synopsis Obstetric Edisi 2 Jilid 1, Buku Kedikteran EGC: Jakarta
Pratiwi, A., Arifah S. 2011, Perilaku Kehamilan , Persalinan Dan Postpartum Terkait Dengan Budaya Kesehatan Pada Masyarakat Jawa Di wilayah Kabupaten Sukoharjo' Jurnal Komunikasi Kesehatan, [Online], Vol. 2 No.01. Dari: Http://E-Journal.AkbidPurworejo.Ac.Id/Index.Php/Jkk 2/Article/View/49 . [9 April 2013]

Suryawati, Chriswardani. 2007, Factor Sosial Budaya Dalam Praktik Perawatan Kehamilan, Persalinan Dan Pasca Persalinan Jurnal Promosi Kesehatan Indonesia, [Online], Vol. 2, No. 1.Dari Http:// Repository.usu.ac.id/ Handle/123456789/17200. [ 2 Maret 2013] 